\title{
Comparative Study on Inhibition of Pancreatic Cancer Cells by Resveratrol Gold Nanoparticles and a Resveratrol Nanoemulsion Prepared from Grape Skin
}

\author{
Baskaran Stephen Inbaraj ${ }^{1,+}+\mathbb{D}$, Leng-Huei Hua ${ }^{1,+}$ and Bing-Huei Chen $1,2, * \mathbb{D}$ \\ 1 Department of Food Science, Fu Jen Catholic University, New Taipei City 24205, Taiwan; \\ 138547@mail.fju.edu.tw (B.S.I.); m3426531@gmail.com (L.-H.H.) \\ 2 Department of Nutrition, China Medical University, Taichung 40401, Taiwan \\ * Correspondence: 002622@mail.fju.edu.tw; Tel.: +886-2-2905-3626; Fax: +886-2-2209-3271 \\ + Equally contributed to this article.
}

check for updates

Citation: Inbaraj, B.S.; Hua, L.-H.; Chen, B.-H. Comparative Study on Inhibition of Pancreatic Cancer Cells by Resveratrol Gold Nanoparticles and a Resveratrol Nanoemulsion Prepared from Grape Skin. Pharmaceutics 2021, 13, 1871. https://doi.org/10.3390/ pharmaceutics13111871

Academic Editors: Jung Min Shin and Eun Sook Lee

Received: 13 September 2021

Accepted: 29 October 2021

Published: 5 November 2021

Publisher's Note: MDPI stays neutral with regard to jurisdictional claims in published maps and institutional affiliations.

Copyright: (c) 2021 by the authors. Licensee MDPI, Basel, Switzerland. This article is an open access article distributed under the terms and conditions of the Creative Commons Attribution (CC BY) license (https:// creativecommons.org/licenses/by/ $4.0 /)$.

\begin{abstract}
Resveratrol, a phenolic compound possessing vital biological activities such as anti-cancer, is present abundantly in grape skin, a waste produced during the processing of grape juice. The objectives of this study were to prepare resveratrol-gold nanoparticles and a resveratrol nanoemulsion from grape skin and study their inhibition effects on pancreatic cancer cells BxPC-3. The spherical-shaped citrate gold nanoparticles (GNPs) and resveratrol-gold nanoparticles (R-GNPs) were, respectively, prepared with a surface plasmon resonance peak at 528 and $538 \mathrm{~nm}$, mean particle size of 20.8 and $11.9 \mathrm{~nm}$, and zeta-potential at -32.7 and $-66.7 \mathrm{mV}$, by controlling an appropriate concentration of citrate/resveratrol and gold chloride as well as stirring time and temperature. The resveratrol nanoemulsion, composed of soybean oil, Tween 80 , and sucrose fatty acid ester in glycerol and water, possessed a high storage stability with a mean particle size of $14.1 \mathrm{~nm}$, zeta-potential of $-49.7 \mathrm{mV}$, and encapsulation efficiency of $95.5 \%$. An antiproliferation study revealed that both R-GNPs and resveratrol nanoemulsion could effectively inhibit the growth of pancreatic cancer cells BxPC-3, with the latter showing a higher inhibition effect. Western blot analysis implied that both can down-regulate expressions of cyclin A, cyclin B, CDK1, and CDK2 and up-regulate expressions of p53 and p21, accompanied by enhancing cytochrome $C$ expression, decreasing BcL-2 expression, increasing Bax expression, and leading to the elevation of caspase- 8 , caspase- 9 , and caspase- 3 activities for cell apoptosis execution. Future research is needed to study the inhibition of pancreatic tumors in vivo by R-GNPs and resveratrol nanoemulsions.
\end{abstract}

Keywords: grape skin; resveratrol-gold nanoparticle; resveratrol nanoemulsion; pancreatic cancer cells BxPC-3; western blotting

\section{Introduction}

Grape, one of the major fruits produced in the world, is rich in many vital nutrients such as vitamins and minerals as well as phytochemicals such as phenolic acids and flavonoids, both of which have been demonstrated to possess important biological activities such as antioxidation, anti-inflammation, cardioprotection, anticancer, and anti-bacteria [1]. Of the various phenolic acids and flavonoids, resveratrol was also shown to exhibit many physiological functions including anti-inflammation, anticancer, neuroprotection, cardioprotection, anti-diabetes, anti-dyslipidemia, anti-aging and anti-rheumatism [2,3]. However, resveratrol can undergo a great loss during the processing of grapes into grape juice, one of the most imperative commercial beverage products on the market worldwide. Nevertheless, grape skin, a by-product obtained during the processing of grape juice and often discarded after processing, was shown to contain a significant amount of resveratrol at 20-100 $\mu \mathrm{g} / \mathrm{g}$ based on dry weight [4]. Thus, it will be of great advantage to the food 
industry if resveratrol in grape skin can be extracted and developed into functional foods or even a botanic drug.

Resveratrol, naturally present in trans and glycosyl form, can be converted to cisresveratrol after exposure to light, which can be more susceptible to heat and light degradations [5]. Moreover, the bioavailability of cis-resveratrol in rats was reported to be lower than that of trans-resveratrol [6]. Also, because of low aqueous solubility, the bioavailability of both trans- and cis-resveratrol in vivo is quite low, and thus the biological activity can be affected greatly [5]. To remedy this problem, many techniques such as nanoemulsions, liposomes, and polymeric nanoparticles have been developed to encapsulate resveratrol to enhance its aqueous solubility and stability in vivo so that the biological activity of resveratrol can be improved substantially [7].

Accordingly, emulsions can be classified into nanoemulsions, microemulsions, and macroemulsions, with the mean particle size ranging from 10 to $100 \mathrm{~nm}, 2$ to $100 \mathrm{~nm}$, and 1 to $100 \mu \mathrm{m}$, respectively [8]. Among the various emulsions, both oil-in-water $(\mathrm{O} / \mathrm{W})$ and water-in-oil (W/O) types are frequently prepared for their wide applications in the field of foods, cosmetics, drugs, and environments. Compared to microemulsions, nanoemulsions have been reported to be more kinetically stable [8], and both can be used as drug delivery systems for the encapsulation of unstable bioactive compounds to enhance biological activity [9]. Furthermore, both microemulsions and nanoemulsions are simple ternary systems composed of water phase, oil phase, and surfactants, with co-solvent and cosurfactant sometimes being used to increase the encapsulation efficiency and stability of both systems [9].

Of the various nanomaterials used in biomedical applications, gold is the most popular one due to its capability in conjugation with drugs to act as a carrier for drug delivery and a contrast agent for imaging enhancement [10]. More importantly, the conjugation of gold nanoparticle with a specific cancer cell surface receptor such as folate has been shown to enhance the efficiency of cancer treatment through active targeting [11]. In addition to active targeting, it is also possible to strengthen cancer therapy efficiency through the conjugation of gold nanoparticles with lipid-based microemulsion or nanoemulsion containing bioactive compounds. For instance, in a previous study, Huang et al. [9] prepared a nanogold-lycopene nanoemulsion with a mean particle size of $21.3 \mathrm{~nm}$ by transmission electron microscope (TEM) analysis, and they demonstrated a substantially higher synergistic effect of this nanoemulsion in inhibiting the growth of colon cancer cells HT-29 than nanogold or lycopene when used alone. More specifically, the TEM image revealed that numerous nanoemulsion-filled vacuoles invaded cytosol and converged into mitochondria, resulting in an abnormally elongated morphology with reduced cristae and matrix contents, demonstrating a possible passive targeting effect in treating colon cancer through the enhanced permeability and retention (EPR) effect [9].

In view of the great impact of nanocomposites on possible treatments of cancer, this study was undertaken to isolate resveratrol from grape skin for preparation of a resveratrol nanoemulsion to explore its inhibition effect on the growth of pancreatic cancer cells BxPC-3. In addition, gold-resveratrol nanoparticles were also prepared to compare their inhibition effect on pancreatic cancer cells BxPC-3.

\section{Materials and Methods}

\subsection{Materials}

Grape skin $(10 \mathrm{~kg})$ was collected from a local fruit juice shop located at Hsinchuang district, New Taipei City, Taiwan. Prior to experiments, the grape skin was freeze-dried and ground into powder $(2 \mathrm{~kg})$. Trans-resveratrol standard was procured from SigmaAldrich Co. (St. Louis, MO, USA). The HPLC-grade solvents including acetonitrile, acetone, and methanol were from Merck Co. (Darmstadt, Germany). Ethyl acetate, hydrochloric acid, sodium bicarbonate, and 99\% ethanol were also from Sigma-Aldrich Co. Deionized water was made using a water purification system from Millipore Co. (Bedford, MA, USA). Sucrose fatty acid ester (S-1570) was from Chen-Fang Co. (Taipei, Taiwan). Both 
Tween 80 and glycerol were from Yu-Pa Co. (Taipei, Taiwan). Gold chloride trihydrate solution, potassium dihydrogen phosphate, trisodium citrate, sodium carbonate, and FolinCiocalteu phenol reagent were also from Sigma-Aldrich Co. A Gemini C18 110A column $(250 \times 4.6 \mathrm{~mm}$ ID, particle size $5 \mu \mathrm{m})$ was from Phenomenex Co. (Torrance, CA, USA).

\subsection{Cell Culture}

Both pancreatic endothelial cells (MS1) and pancreatic cancer cells (BxPC-3) were from the Bioresource Collection and Research Center, Taiwan Food Industry Research and Development Institute (Hsinchu, Taiwan). Dulbecco's modified Eagle medium (DMEM), Rosewell Park Memorial Institute (RPMI) medium 1640, fetal bovine serum (FBS), 4(2-hydroxyethyl)-1-piperazineethanesulfonic acid (HEPES) solution, phosphate buffered solution (PBS), sodium pyruvate solution, Hank's balanced salt solution (HBSS), Dulbecco's phosphate buffer solution (DPBS), and $0.25 \%$ trypsin-EDTA were all from Hyclone Co. (Logan, UT, USA). Bovine serum albumin (BSA), sodium dodecyl sulfate (SDS), $\beta$-mercaptoethanol, bromophenol, $0.4 \%$ trypan blue, thiazolyl blue tetrazolium bromide (MTT), and ethylenediaminetetraacetic acid (EDTA) were from Sigma-Aldrich Co. Dimethyl sulfoxide (DMSO) was from Merck Co. (Taipei, Taiwan). Ammonium persulfate (APS), glycine, $N, N, N^{\prime}, N^{\prime}$-tetramethylethylenediamine (TEMED), tris(hydroxymethyl)aminomethane (Tris), and 30\% acrylamide were from USB Co. (Cleveland, OH, USA). Both Bradford reagent (protein assay) and Clarity Western ECL substrate were from Bio-Rad Co. (Hercules, CA, USA). HyBlock blocking buffer was from Han-Hsin Co. (Taipei, Taiwan). Caspase-3, caspase-8, and caspase-9 assay kits were from Bio Vision Co. (Milpitas, CA, USA). Primary antibodies including cytochrome C, p21, BcL-2, p53, cyclin B, cyclin A, CDK1, and $\beta$-actin were from Biotools Co. (New Taipei City, Taiwan), while Bax and CDK2 were from Santa Cruz Biotechnologies Co. (Santa Cruz, CA, USA). Secondary antibodies including anti-mouse-IgG-HRP and anti-rabbit-IgG-HRP were also from Biotools Co. (New Taipei City, Taiwan).

\subsection{Instruments}

The HPLC-MS instrument, composed of a degasser (G1379B), quaternary pump (G1312B), autoinjector (G1329B), column temperature controller (G1316B), photodiode array detector (PDA) (G1315C), and single quadrupole mass spectrometers (6130) with atmospheric pressure chemical ionization (APCI) detection mode, was from Agilent Technologies (Santa Clara, CA, USA). The high-speed centrifuge (Sorvall RC5C) was from Du Pont Co. (Wilmington, DL, USA), while the microcentrifuge (Fresco 21) was from Thermo Fisher Scientific Co. (San Jose, CA, USA). The rotary evaporator (N-1200A) was from Eyela Co. (Tokyo, Japan). The sonicator (DC400H) was from Asiatek Co. (Taipei, Taiwan). The dynamic light scattering instrument was from Brookhaven Co. (Holtsville, NY, USA). The zeta potential analyzer was from Horiba Scientific Co. (Kyoto, Japan). The transmission electron microscope (TEM) was from JEOL Co. (Tokyo, Japan). The inverted microscope (Eclipse TS 100) was from Nikon Co. (Tokyo, Japan). The ELISA reader was from Molecular Devices Co. (Sunnyvale, CA, USA). The multimode microplate reader (Infinite 200 PRO) was from TECAN Co. (Zürich, Switzerland). The electrophoresis system was from Bio-Rad Laboratories (Hercules, CA, USA). The spectrophotometer (DU70) was from Beckman Co. (Fullerton, CA, USA). The luminescence/fluorescence imaging system (MGIS-21-C2-1M) was from Top Bio Co. (New Taipei City, Taiwan). The $\mathrm{CO}_{2}$ incubator (MCO-20AIC) was from Panasonic Co. (Osaka, Japan).

\subsection{Extraction of Resveratrol from Grape Skin}

A method based on Wang et al. [12] was modified to extract resveratrol from grape skin. Initially a $40 \mathrm{~g}$ sample of grape skin powder was mixed with $400 \mathrm{~mL}$ of $95 \%$ ethanol, after which this mixture was extracted in a $75^{\circ} \mathrm{C}$ water bath for $1 \mathrm{~h}$ and this procedure was repeated twice. After centrifugation at $3800 \times g$ for $30 \mathrm{~min}$, the supernatant was collected and evaporated to dryness, followed by dissolving in $150 \mathrm{~mL}$ of deionized water, sonicating 
for $20 \mathrm{~min}$, filtering through a filter paper, adjusting $\mathrm{pH}$ to 1 with $1 \mathrm{M}$ hydrochloric acid, and stirring for $3 \mathrm{~h}$. Then, the extractant $(50 \mathrm{~mL})$ was collected and mixed with ethyl acetate $(50 \mathrm{~mL})$ in a separatory funnel for separation into two layers and the organic layer was collected. This procedure was repeated 3 times and all the organic layers were pooled in a separatory funnel, followed by adding $5 \%$ sodium bicarbonate solution ( $\mathrm{pH} 8-9)$ at a volume ratio of $1: 1$, washing until the organic layer became colorless, evaporating to dryness, dissolving in $0.5 \mathrm{~mL}$ of methanol, and filtering through a $0.22 \mu \mathrm{m}$ membrane filter for HPLC analysis. Trans-resveratrol and cis-resveratrol in the grape skin were separated, identified, and quantified using a method described in a previous study [13].

\subsection{Preparation of Resveratrol Nanoemulsion}

Initially $5 \mathrm{~mL}$ of resveratrol extract was collected from the organic layers shown above and evaporated to dryness under nitrogen, followed by adding $0.1 \mathrm{~g}$ soybean oil $(1 \%)$ containing vitamin $\mathrm{E}(1 \%)$, stirring for complete mixing, adding $0.7 \mathrm{~g}$ Tween $80(7 \%)$ and $0.4 \mathrm{~g}$ sucrose fatty acid ester in glycerol $(4 \%)$ and stirring again. Then $8.8 \mathrm{~g}$ deionized water $(88 \%)$ was added and the mixture was sonicated for $1 \mathrm{~h}$ to obtain a transparent resveratrol nanoemulsion containing resveratrol at $200 \mathrm{mg} / \mathrm{mL}$.

\subsection{Characteristics Determination of Resveratrol Nanoemulsion}

For particle size and polydispersity determination, a portion $(10 \mu \mathrm{L})$ of the resveratrol nanoemulsion was collected and diluted 100-fold with a potassium dihydrogen phosphate solution, after which a portion was poured into a colorimetric tube for determination by a dynamic light scattering instrument (DLS) with the BIC particle sizing 90Plus software system. For zeta potential determination, a portion $(10 \mu \mathrm{L})$ of the resveratrol nanoemulsion was diluted with deionized water 100 -fold, and a $300 \mu \mathrm{L}$ sample was placed in an analysis cell for determination by a zeta potential analyzer. The TEM image of the resveratrol nanoemulsion was determined by diluting the resveratrol nanoemulsion with deionized water 200-fold and a portion $(20 \mu \mathrm{L})$ was placed on a copper grid for sinking for $1 \mathrm{~min}$, followed by removing excess sample with a filter paper, negative staining with $2 \%$ phosphotungstic acid for $45 \mathrm{~s}$, removing excess staining agent, drying in a desiccator, and observing the image under $120 \mathrm{kV}$ by enlarging $3 \times 10^{5}$ times. Then, both the size and shape of the resveratrol nanoemulsion were obtained. Also, the encapsulation efficiency was determined by collecting a portion $(100 \mu \mathrm{L})$ of the resveratrol nanoemulsion and diluting it with deionized water 10 times, followed by pouring into a centrifuge tube containing a $3 \mathrm{kDa}$ dialysis membrane, centrifuging at $12,000 \times \mathrm{g}$ for $20 \mathrm{~min}\left(25^{\circ} \mathrm{C}\right)$, collecting the lower layer $(200 \mu \mathrm{L})$ containing free resveratrol, evaporating to dryness, and dissolving in methanol for HPLC analysis of resveratrol [13]. Then, the encapsulation efficiency of resveratrol was obtained by using a formula described in a previous study [14].

\subsection{Stability of Resveratrol Nanoemulsion}

The resveratrol nanoemulsion was stored at $4{ }^{\circ} \mathrm{C}$ for 90 days, during when a portion was collected every 15 days for determination of particle size and polydispersity index by DLS, as well as zeta potential by a zeta potential analyzer. Similarly, a portion $(200 \mu \mathrm{L})$ was collected and placed in a $40{ }^{\circ} \mathrm{C}, 60^{\circ} \mathrm{C}, 80^{\circ} \mathrm{C}$, and $100{ }^{\circ} \mathrm{C}$ water bath separately for heating for $0.5,1,1.5$, or $2 \mathrm{~h}$, after which both the particle size and polydispersity index of each sample were determined by DLS, while zeta potential was analyzed by a zeta potential analyzer.

\subsection{Preparation of Gold Nanoparticle (GNPs) and Resveratrol-Gold Nanoparticle (R-GNPs)}

A method based on Kimling et al. [15] and Inbaraj et al. [16] was modified to prepare the GNPs. One mL of gold (III) chloride trihydrate solution was mixed with $1 \mathrm{~mL}$ of deionized water in a tube, followed by heating on a plate at $75^{\circ} \mathrm{C}$ and stirring for $20 \mathrm{~min}$ at $1000 \mathrm{rpm}$ Then, $3 \mathrm{~mL}$ of $5 \mathrm{mM}$ sodium citrate solution was added with continued heating and stirring until the solution color turned red, and $5 \mathrm{~mL}$ of the GNPs was obtained. 
Likewise, a method based on Thipe et al. [17] was modified to prepare the R-GNPs. Two mL of gold(III) chloride trihydrate solution was mixed with $2 \mathrm{~mL}$ of deionized water in a tube, followed by heating on a plate at $40{ }^{\circ} \mathrm{C}$ and stirring at $1000 \mathrm{rpm}$ for $20 \mathrm{~min}$. Then, $1 \mathrm{~mL}$ of resveratrol standard solution $(5 \mathrm{mM})$ was added with continued heating and stirring until the solution color turned red, and $5 \mathrm{~mL}$ of R-GNPs was prepared.

\subsection{Characteristics Determination of GNPs and R-GNPS}

For determination of the absorption spectra, gold(III) chloride trihydrate solution, GNPs and R-GNPs were each diluted with deionized water 10-fold, after which $2 \mathrm{~mL}$ of each sample was collected in a colorimetric tube for determination by a spectrophotometer. For zeta potential determination, $100 \mu \mathrm{L}$ of the GNPs and R-GNPs were collected separately and diluted with deionized water 10 -fold, after which $300 \mu \mathrm{L}$ of each sample was poured into a cell for determination by a zeta potential analyzer. Also, for TEM imaging, samples of the GNPs and R-GNPs were collected separately and diluted with deionized water 50 times, after which $20 \mu \mathrm{L}$ of each sample was placed on a copper grid for sinking for $1 \mathrm{~min}$, followed by removing excess sample with a filter paper, drying in a desiccator, and observing the image under $120 \mathrm{kV}$ by enlarging $3 \times 10^{5}$ times. The resveratrol concentration in the R-GNPs was determined based on a method by Thipe et al. [17] with some modifications. Initially, six concentrations of resveratrol standard $(7.8,15.6,31.2,62.5,125$, and 250 ppm) were prepared, after which $0.5 \mathrm{~mL}$ of each and R-GNPs were collected separately in a $15 \mathrm{~mL}$ centrifuge tube, followed by adding $0.5 \mathrm{~mL}$ of Folin-Ciocalteu phenol agent, mixing thoroughly, reacting in the dark for $5 \mathrm{~min}$, adding $1 \mathrm{~mL}$ of sodium carbonate solution (7\%), mixing thoroughly, reacting in the dark for $1 \mathrm{~h}$, and measuring absorbance at $750 \mathrm{~nm}$ with an ELISA reader. Then, the resveratrol concentration in the R-GNPs was obtained based on the standard curve of resveratrol standard.

\subsection{Cell Culture Experiment}

Pancreatic cancer cells BxPC-3 were cultured in RPMI 1640 medium containing 2 mM L-glutamine, $1.5 \mathrm{~g} / \mathrm{L}$ sodium bicarbonate, $1.0 \mathrm{mM}$ sodium pyruvate, $4.5 \mathrm{~g} / \mathrm{L}$ glucose, $10 \mathrm{mM}$ HEPES, and 10\% FBS, while pancreatic endothelial cells MS1 was cultured in DMEM medium containing $4 \mathrm{mM}$ L-glutamine, $1.5 \mathrm{~g} / \mathrm{L}$ sodium bicarbonate, $4.5 \mathrm{~g} / \mathrm{L}$ glucose, $1.0 \mathrm{mM}$ sodium pyruvate and 5\% FBS. After collection from liquid nitrogen, cells were thawed at $37^{\circ} \mathrm{C}$ and cells containing $7 \%$ DMSO were added to a $10 \mathrm{~cm}$ plate, followed by adding $10 \mathrm{~mL}$ of medium and culturing in an incubator with a temperature of $37^{\circ} \mathrm{C}$, relative humidity of $100 \%$, and carbon dioxide at $5 \%$. After cells reached a confluency of $80-90 \%$, PBS was added for washing 2-3 times and then $2 \mathrm{~mL}$ of $0.25 \%$ trypsin-EDTA added for reaction in an incubator for 3-5 min. Next, $2 \mathrm{~mL}$ of medium was added and centrifuged at $1500 \times g$ for $4 \mathrm{~min}$, followed by removing the supernatant, adding $1 \mathrm{~mL}$ of medium, and collecting a portion of the cells cultured in a new medium for further counting under a microscope.

\section{MTT Assay}

Cells containing BxPC-3 or MS1 were seeded in a 96-well plate with each well containing $3 \times 10^{3}$ cells and cultured $48 \mathrm{~h}$ for cell adhesion, after which the medium was removed and replaced with different concentrations $(1.25,2.5,5,10,15$, and $20 \mu \mathrm{g} / \mathrm{mL})$ of the GNPs, R-GNPs, resveratrol standard, or resveratrol nanoemulsion. After $48 \mathrm{~h}$ of incubation, the medium was removed and MTT $(200 \mu \mathrm{L})$ added for reaction for $1 \mathrm{~h}$, followed by adding $100 \mu \mathrm{L}$ of DMSO, stirring to dissolve purple crystal, and measuring absorbance at $570 \mathrm{~nm}$ with an ELISA reader for the determination of cell viability [9].

\subsection{Western Blotting}

BxPC-3 cells $\left(1 \times 10^{6}\right)$ were seeded in a $10 \mathrm{~cm}$ plate and cultured overnight for cell adhesion. Then, the medium was removed and replaced with three concentrations (10, 15 , and $20 \mu \mathrm{g} / \mathrm{mL}$ ) of the resveratrol nanoemulsion or R-GNPs for incubation for $48 \mathrm{~h}$. 
Following medium removal and washing with PBS, $2 \mathrm{~mL}$ of $0.25 \%$ trypsin-EDTA was added for centrifugation at $1500 \times g$ for $4 \mathrm{~min}$. Then, the supernatant was removed, followed by adding $100 \mu \mathrm{L}$ of cell lysis buffer, standing overnight at $-20^{\circ} \mathrm{C}$, centrifuging again at $12,000 \mathrm{rpm}$ for $30 \mathrm{~min}\left(4^{\circ} \mathrm{C}\right)$, and collecting the supernatant as the protein extract. For protein quantitation, eight concentrations of bovine serum albumin (BSA) standards $(0,100,200,400,500,600,800$, and $1000 \mu \mathrm{g} / \mathrm{mL})$ were prepared and $10 \mu \mathrm{L}$ of each was collected in a 96-well plate, followed by adding $200 \mu \mathrm{L}$ of Bradford reagent for reaction for $5 \mathrm{~min}$, measuring absorbance at $595 \mathrm{~nm}$ with an ELISA reader, preparing the standard curve by plotting concentration against absorbance, and finally the protein in the cell extract was quantified based on the standard curve. Next, a sample of protein extract was collected and sample buffer added for reaction in a $98{ }^{\circ} \mathrm{C}$ water bath for $10 \mathrm{~min}$. After cooling on ice, the samples were added in a tank for protein separation with the upper voltage being $90 \mathrm{~V}$ ( $20 \mathrm{~min}$ ) and the lower voltage being $110 \mathrm{~V}(80 \mathrm{~min})$. Then, the PVDF membrane was soaked in methanol for $10 \mathrm{~min}$, followed by soaking in transfer buffer, incubating at $4{ }^{\circ} \mathrm{C}$ for $3 \mathrm{~h}(100 \mathrm{~V})$, soaking in blocking buffer, removing blocking buffer, and washing with TBST 5 times for $15 \mathrm{~min}$ each. The primary antibodies was added as follows: cytochrome C (1:1250), p21 (1:500), BcL-2 (1:1250), p53 (1:500), cyclin B (1:500), cyclin A (1:500), CDK1 (1:500), Bax (1:500), CDK2 (1:500), and $\beta$-actin (1:1250). Following reaction at $4{ }^{\circ} \mathrm{C}$ overnight, TBST was added for washing 5 times for $15 \mathrm{~min}$ each and the horseradish peroxidase (HRP)-conjugated secondary antibody (IgG) was added for reaction at $4{ }^{\circ} \mathrm{C}$ for $2 \mathrm{~h}$, followed by washing with TBST 5 times for $15 \mathrm{~min}$ each, adding ECL reagent for reaction, and detection by a fluorescence imaging system. Following Western blotting, a band was circled and the value determined automatically by a fluorescence imaging software system (ImageJ), followed by dividing by a marker value to obtain a number. Then, the number was divided by the control value to obtain the expression values.

\subsection{Activities of Caspase-3, Caspase-8, and Caspase-9}

All the activities of caspase-3, caspase- 8 , and caspase- 9 were determined by a fluorometric assay kit. In brief, the caspase- 3 activity was determined by collecting cell extract $(25 \mu \mathrm{L})$, adding $50 \mu \mathrm{L}$ of $2 X$ reaction buffer containing $5 \mu \mathrm{L}$ of Ac-DEVD-AMC substrate, reacting in a $37^{\circ} \mathrm{C}$ water bath for $1 \mathrm{~h}$, and transferring to a 96-well plate for measuring absorbance with an excitation wavelength at $400 \mathrm{~nm}$ and emission wavelength at $505 \mathrm{~nm}$ by a multimode microplate reader. Similarly, the activities of caspase- 8 and caspase- 9 were determined by collecting cell extract $(25 \mu \mathrm{L})$, followed by adding $50 \mu \mathrm{L}$ of $2 \mathrm{X}$ reaction buffer containing $10 \mathrm{mM}$ DTT and $5 \mu \mathrm{L}$ of $1 \mathrm{mM}$ IETD-AFC substrate for caspase- 8 or $1 \mathrm{mM}$ LEHD-AFC substrate for caspase-9, reacting in a $37^{\circ} \mathrm{C}$ water bath for $1 \mathrm{~h}$, transferring to a 96-well plate, and measuring absorbance with an excitation wavelength at $400 \mathrm{~nm}$ and emission wavelength at $505 \mathrm{~nm}$ by a multimode microplate reader.

\subsection{Statistical Analysis}

All the data were subjected to statistical analysis by SAS [18] for ANOVA analysis and Duncan's multiple range test for significance in mean comparison $(p<0.05)$.

\section{Results and Discussion}

\subsection{Analysis of Trans-Resveratrol and Cis-Resveratrol in Grape Skin}

Based on the extraction and HPLC method described in a previous study [13], a total of five trans-resveratrol and related stilbenes in grape skin were identified and quantified, with cis-piceid present in the largest amount $(4.185 \mu \mathrm{g} / \mathrm{g})$, followed by trans-piceid $(1.643 \mu \mathrm{g} / \mathrm{g})$, trans-resveratrol $(1.539 \mu \mathrm{g} / \mathrm{g}), \varepsilon$-viniferin $(1.056 \mu \mathrm{g} / \mathrm{g})$, and cis-resveratrol $(0.293 \mu \mathrm{g} / \mathrm{g})$.

\subsection{Characteristics of Resveratrol Nanoemulsion}

Figure 1A shows the bright red appearance of the resveratrol nanoemulsion, with the mean particle size and polydispersity index (PDI) being $14.1 \mathrm{~nm}$ (Figure 1B) and 0.296, respectively, as determined by DLS. This outcome implies a monodispersion of nanopar- 
ticles in this resveratrol nanoemulsion because of low PDI. Also, the TEM image shows round-shaped nanoparticles with the mean particle size of $15 \mathrm{~nm}$ (Figure 1C), which was slightly higher than that determined by DLS. In several previous studies, Sessa et al. [19] prepared a resveratrol nanoemulsion composed of peanut oil, ethanol, lecithin, sucrose fatty acid ester, and deionized water with the mean particle size of $137.5 \mathrm{~nm}$ and PDI of 0.22 , respectively. Similarly, Kumar et al. [20] prepared a resveratrol nanoemulsion composed of ethyl oleate, lecithin, Tween 80 , and deionized water with the mean particle size and PDI being $18 \mathrm{~nm}$ and 0.228 , respectively. More recently, by using oregano essential oil, Tween 80, ethanol, and deionized water, a resveratrol nanoemulsion with particle size at $137.5 \mathrm{~nm}$ and PDI at 0.22 was prepared [21]. By comparison, the mean particle size of the resveratrol nanoemulsion prepared in our study was smaller, which should be due to the difference in components used for its preparation. In addition, this resveratrol nanoemulsion showed a high stability as evident by the zeta potential being $-49.7 \mathrm{mV}$ based on a report by Shnoudeh et al. [22], stating that the zeta potential should be $>30 \mathrm{mV}$ or $<-30 \mathrm{mV}$ to maintain a high nanoemulsion stability. Also, the encapsulation efficiency was $95.5 \%$, which was higher than that $(93.4 \%)$ reported by Zhou et al. [23], who prepared a resveratrol nanoemulsion composed of soybean oil, lecithin, poloxamer 188, Labrasol, and deionized water.
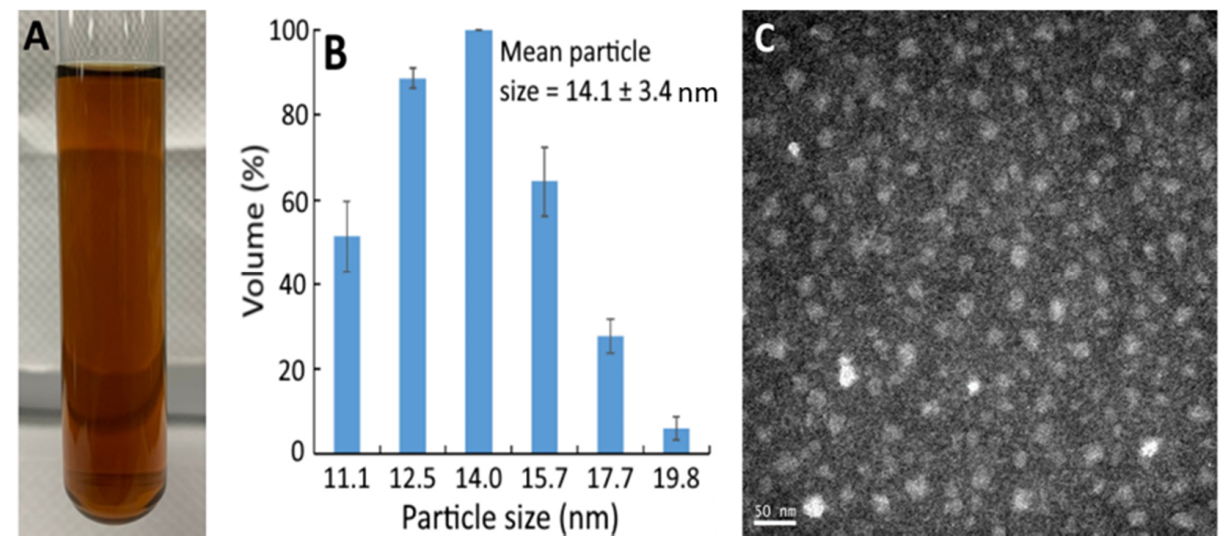

Figure 1. Appearance of resveratrol nanoemulsion prepared from grape skin (A) and its particle size distribution as determined by dynamic light scattering method (B) as well as the transmission microscopic image obtained at $120 \mathrm{kV}$ (C). The resveratrol nanoemulsion with a mean particle size of $14.1 \pm 3.4 \mathrm{~nm}$ and polydispersity index of 0.296 was prepared by mixing $1 \%$ soybean oil, $7 \%$ Tween $80,4 \%$ sucrose fatty acid ester in glycerol, and $88 \%$ water.

\subsection{Stability of Resveratrol Nanoemulsion}

Only a slight change in particle size, PDI, and zeta potential was shown in the resveratrol nanoemulsion over a 90 -day storage period at $4{ }^{\circ} \mathrm{C}$, with the values ranging from 12.0 to $13.6 \mathrm{~nm}, 0.150$ to 0.296 , and -41.6 to $-57.4 \mathrm{mV}$, respectively, revealing a high stability of this resveratrol nanoemulsion at low temperature. Although the zeta potential values varied from -41.6 to $-57.4 \mathrm{mV}$ during 90 -day storage at $4{ }^{\circ} \mathrm{C}$, it did not affect the stability of the resveratrol nanoemulsion, as a zeta potential value $>30 \mathrm{mV}$ or $<-30 \mathrm{mV}$ was used as an indicator of high stability as mentioned above [22]. However, during heating at $40-100{ }^{\circ} \mathrm{C}$ for $0.5-2 \mathrm{~h}$, a slight change in particle size from 12.0 to $17.1 \mathrm{~nm}$ occurred (Table S1, see Supplementary Materials), while a pronounced decrease in zeta potential was observed following heating at $100{ }^{\circ} \mathrm{C}$ for $>0.5 \mathrm{~h}$. Thus, the heating temperature has to be controlled at $80^{\circ} \mathrm{C}$ to maintain a high thermal stability of this resveratrol nanoemulsion.

\subsection{Characteristics of GNPs and R-GNPS}

Figure 2 shows the red appearance of both the GNPs and R-GNPs (Figure 2A) as well as the UV-VIS spectra of the gold chloride trihydrate solution, gold nanoparticle (GNPs), and resveratrol-gold nanoparticles (R-GNPs), with the maximum absorption 
wavelength of the surface plasmon resonance (SPR) peak of the GNPs and R-GNPs being 528 and $538 \mathrm{~nm}$, respectively (Figure 2B). Similar findings were reported for resveratrolgold nanoparticles by Tomoaia et al. [24], Park et al. [25], and Zhang et al. [26], showing the maximum absorbance of the SPR peaks to be 538, 540, and $539 \mathrm{~nm}$, respectively. Also, a high stability of the GNPs and R-GNPs was shown as evident by a zeta potential of $-32.7 \mathrm{mV}$ and $-66.7 \mathrm{mV}$, respectively. The TEM images of the GNPs and R-GNPs are shown in Figure 2C,E, respectively, with the mean particle size being $20.8 \mathrm{~nm}$ (Figure 2D) for the former and $11.9 \mathrm{~nm}$ (Figure 2F) for the latter, as well as a round shape for both. The particle size of the R-GNPs was smaller than that reported by Tomoaia et al. [24], Park et al. [25], and Zhang et al. [26], who reported the particle size of R-GNPs to be $50,22.28$, and $39 \mathrm{~nm}$, respectively. This difference may be caused by the variation in preparation steps and conditions.
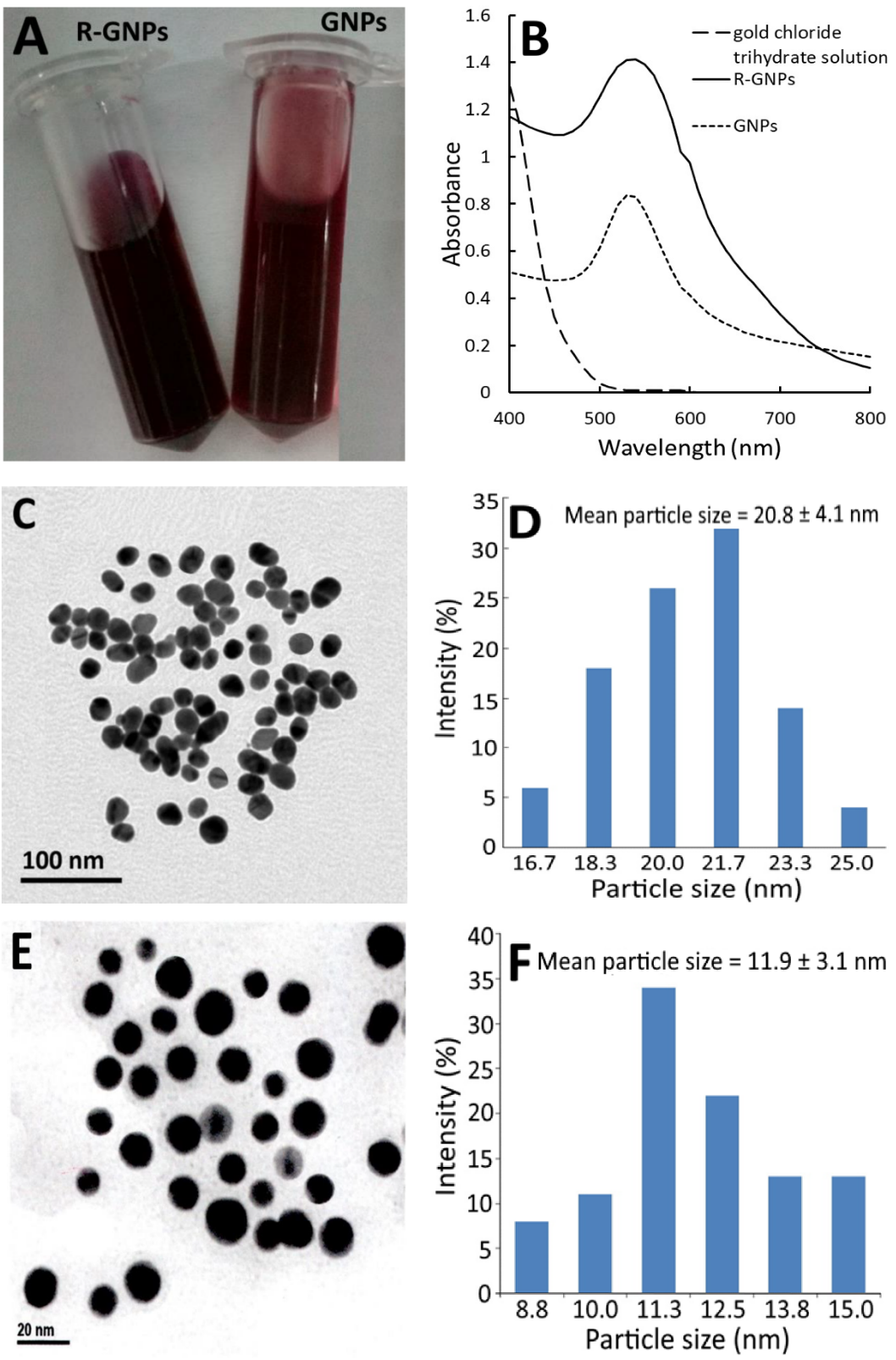

Figure 2. Appearance of gold nanoparticles (GNPs) and resveratrol-gold nanoparticles (R-GNPs) (A) and their absorption spectra showing the surface plasmon resonance peak, respectively, at 528 and $538 \mathrm{~nm}$ (B) as well as the transmission microscopic image obtained at $120 \mathrm{kV}(\mathbf{C}, \mathbf{E})$ along with particle size distribution (D,F) for GNPs (C,D) and R-GNPs (E,F). 


\subsection{Tolerance of Solvent and Blank Nanoemulsion towards Cells}

Figure 3 shows the effect of different concentration of $99 \%$ ethanol on the growth of pancreatic normal cells MS1 (A) and pancreatic cancer cells BxPC-3 (B). A dose-dependent decrease in the cell viability of MS1 was shown following treatment with $99 \%$ ethanol from 0.125 to $2 \%$; however, there was no significant difference $(p>0.05)$ among the six doses. Similarly, a dose-dependent decline in the cell viability of BxPC-3 was observed following treatment with $99 \%$ ethanol from 0.125 to $1.5 \%$, and there was a significant difference $(p<0.05)$ between $2 \%$ ethanol $(99 \%)$ and the other five doses. By comparison at the same dose, 99\% ethanol showed a higher inhibition effect against MS1 than BxPC-3 cells, implying that $99 \%$ ethanol at a dose from 0.125 to $1.5 \%$ possessed a slight toxicity towards MS1 cells, but not BxPC-3 cells.
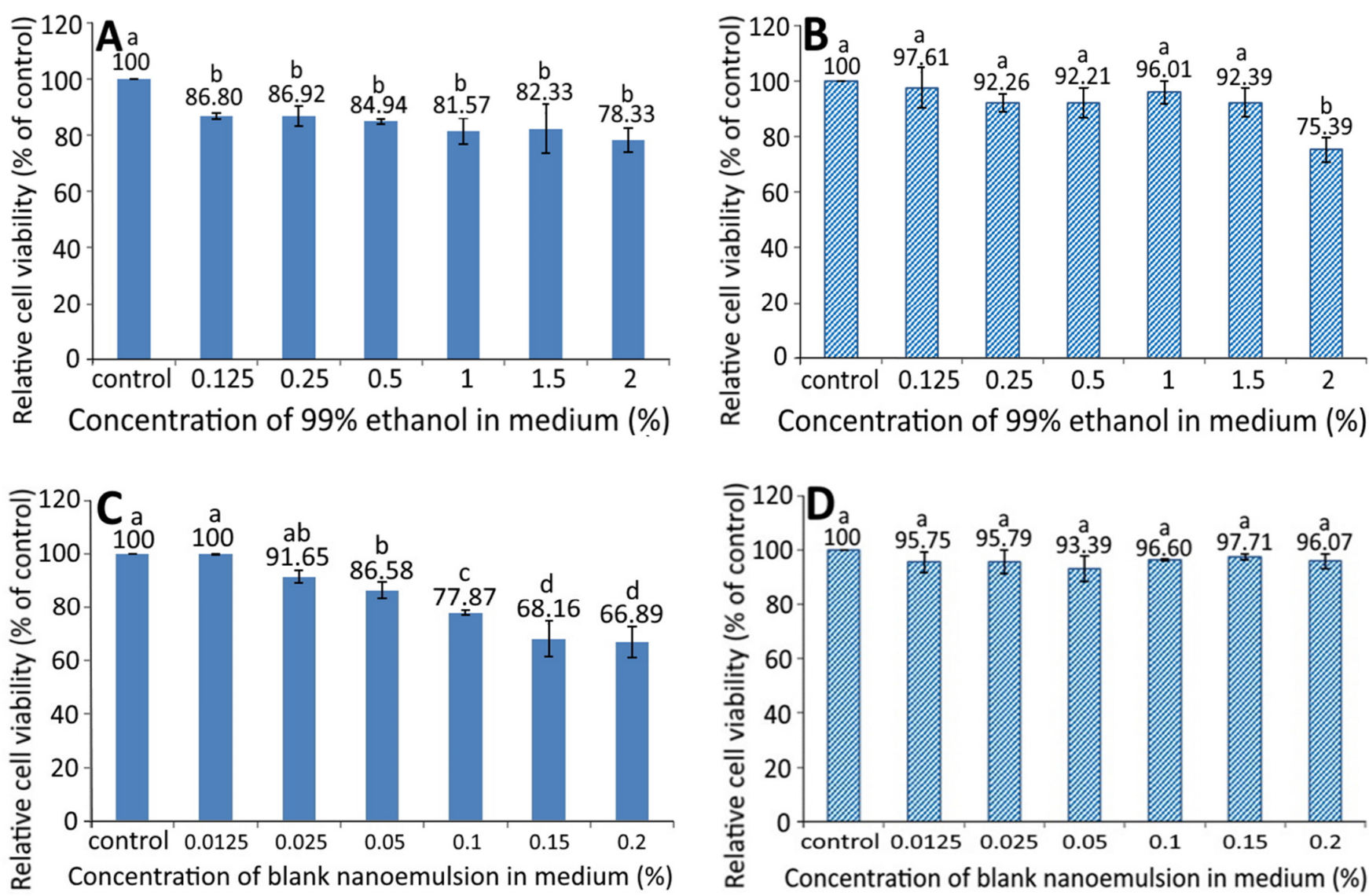

Figure 3. Effect of different concentrations of $99 \%$ ethanol and blank nanoemulsion (without resveratrol) on the growth of pancreatic normal cells MS1 (A,C) and pancreatic cancer cells BxPC-3 (B,D) after $48 \mathrm{~h}$ incubation as measured by MTT assay. Control represents that cells were incubated in RPMI medium only. Data are shown as mean \pm standard deviation $(n=3)$ and data with different small letters ( $\mathrm{a}-\mathrm{d}$ ) are significantly different at $p<0.05$.

The growth of MS1 and BxPC-3 cells as affected by different concentrations of blank nanoemulsions, is shown in Figure 3C,D, respectively. A dose-dependent decline in the cell viability of MS1 was shown following treatment with blank nanoemulsion (in medium) at a dose from 0.0125 to $0.2 \%$ and the decrease became significant $(p<0.05)$ after the level reached $0.05 \%$ and above as compared to the control. However, for BxPC- 3 cells, the viability showed no significant difference $(p>0.05)$ between the control and the other six doses $(0.0125-0.2 \%)$. Comparatively, the blank nanoemulsion showed a higher toxicity against MS1 cells than BxPC-3 cells at the same dose. Thus, both doses of $99 \%$ ethanol and the blank nanoemulsion were, respectively, controlled at $1.5 \%$ and $0.05 \%$ for MS1 cells as well as $1.5 \%$ and $0.2 \%$ for BxPC-3 cells for subsequent experiments. 
3.6. Effects of Different Concentrations of the GNPs, R-GNPs, and Resveratrol Nanoemulsion on the Growth of MS1 and BxPC-3 Cells

Figure 4 shows the effect of different concentrations of GNPs (A and B) and R-GNPs (C and D) on the growth of pancreatic normal cells MS1 (A and C) and pancreatic cancer cells BxPC-3 (B and D). A dose-dependent decrease in viability was shown for both MS1 (Figure 4A) and BxPC-3 (Figure 4B) cells following treatment with the GNPs at a dose from 2.5 to $20 \mu \mathrm{g} / \mathrm{mL}$. By comparison, at the same dose, the GNPs showed a higher toxicity against MS1 cells than BxPC-3 cells. Also, the difference between the control and GNPs at $2.5 \mu \mathrm{g} / \mathrm{mL}$ was not significantly different $(p>0.05)$ for either MS1 or BxPC-3 cells; however, this difference became significant $(p<0.05)$ after the level of GNPs reached $5 \%$ and above. Likewise, a dose-dependent decline in viability was shown for both MS1 and BxPC-3 cells following treatment with the R-GNPs at a dose from 2.5 to $20 \mu \mathrm{g} / \mathrm{mL}$ (resveratrol) and 6.66 to $52.78 \mu \mathrm{g} / \mathrm{mL}$ (gold). Also, the difference between the control and the other five doses was significantly different $(p<0.05)$ for both MS1 and BxPC-3 cells. By comparison at the same dose $(2.5,10$, and $15 \mu \mathrm{g} / \mathrm{mL}$ of resveratrol and $6.66,26.3$, and $39.63 \mu \mathrm{g} / \mathrm{mL}$ of gold), the R-GNPs showed a higher toxicity against MS1 cells than BxPC- 3 cells, but a reversed trend occurred for the doses at 5 and $20 \mu \mathrm{g} / \mathrm{mL}$ of resveratrol as well as at 13.15 and $52.78 \mu \mathrm{g} / \mathrm{mL}$ of gold. Compared to the GNPs at the same dose, the incorporation of resveratrol into the GNPs seemed to decrease the viability of both MS1 and BxPC-3 cells, indicating that resveratrol may possess a higher toxicity towards both MS1 and BxPC-3 cells than GNPs. This phenomenon was further confirmed in Figure 5A,B, showing a pronounced dose-dependent decline in the viability of both MS1 and BxPC3 cells following the treatment of resveratrol standard at $1.25-20 \mu \mathrm{g} / \mathrm{mL}$. Compared to BxPC-3 cells, resveratrol standard showed a much higher inhibition effect against MS1 cells at the same dose. However, this inhibition effect was drastically reduced for MS1 cells following treatment with the resveratrol nanoemulsion at the same dose (Figure 5C), revealing that the nanoemulsion composition, such as soybean oil and sucrose ester, may provide a protective effect towards MS1 cells. Also, resveratrol standard was more effective than the resveratrol nanoemulsion in inhibiting MS1 cells, as evident by an $\mathrm{IC}_{50}$ of 1.73 and $3.75 \mu \mathrm{g} / \mathrm{mL}$, respectively. However, for BxPC-3 cells, the resveratrol nanoemulsion could elevate viability at a dose from $1.25-10 \mu \mathrm{g} / \mathrm{mL}$ as compared to resveratrol standard (Figure 5D), demonstrating again the protective effect of soybean oil and sucrose ester towards BxPC-3 cells. Collectively, resveratrol standard may exhibit a higher toxicity towards pancreatic normal cells MS1 than pancreatic cancer cells BxPC-3. Nevertheless, the resveratrol nanoemulsion was more effective than resveratrol standard in inhibiting BxPC-3 cells as evident by an $\mathrm{IC}_{50}$ of 11.02 and $13.75 \mu \mathrm{g} / \mathrm{mL}$, respectively.

In published reports, most studies are focused on the effect of resveratrol standard on the inhibition of cancer cells. For instance, Cui et al. [27] studied the effect of resveratrol standard $(5-200 \mu \mathrm{M})$ on the inhibition of pancreatic cancer cells AsPC-1, BxPC-3, and PANC- 1 and the $\mathrm{IC}_{50}$ was shown to be $78.3 \mu \mathrm{M}(17.87 \mu \mathrm{g} / \mathrm{mL}), 76.1 \mu \mathrm{M}(17.37 \mu \mathrm{g} / \mathrm{mL})$, and $123.3 \pm 6.5 \mu \mathrm{M}(28.14 \mu \mathrm{g} / \mathrm{mL})$, respectively. For some other types of cancer cells, the $\mathrm{IC}_{50}$ was $24.74 \mu \mathrm{g} / \mathrm{mL}$ for hepatoma cells HepG2 following treatment with resveratrol standard (1-16 $\mu \mathrm{g} / \mathrm{mL}$ ). However, no toxicity was shown towards breast cancer cells MDA-MB231 and MCF-7/adr in the presence of resveratrol standard at $50 \mu \mathrm{M}(11.41 \mu \mathrm{g} / \mathrm{mL})$ [28]. Interestingly, a higher resveratrol dose at $100 \mu \mathrm{M}(22.82 \mu \mathrm{g} / \mathrm{mL})$ decreased the viability of MCF-7/adr cells, while MDA-MB-231 cells remained unaffected [28]. In another study, Zhang et al. [26] studied the effect of resveratrol standard $(1-16 \mu \mathrm{g} / \mathrm{mL})$ on the growth of normal liver cells L02, and an inhibition percentage of $83 \%$ was shown after $24 \mathrm{~h}$ of incubation. However, the inhibition percentage decreased to $<35 \%$ following treatment with resveratrol-nanogold, implying a lower toxicity towards L02 cells after the conjugation of nanogold with resveratrol standard. This outcome is similar to our finding that the resveratrol nanoemulsion was less toxic to pancreatic normal cells MS1 than resveratrol standard as evident by a higher $\mathrm{IC}_{50}$ of the former. Furthermore, compared to several previous studies shown above, the resveratrol nanoemulsion prepared in our study was 
more effective in inhibiting pancreatic cancer cells BxPC-3 than resveratrol standard as shown by a much lower $\mathrm{IC}_{50}$ of the former. Nevertheless, the cytotoxicity of resveratrol towards several other types of normal cells such as keratinocytes [29], smooth muscle cells [30], and endothelial cells [31] cannot be ignored.
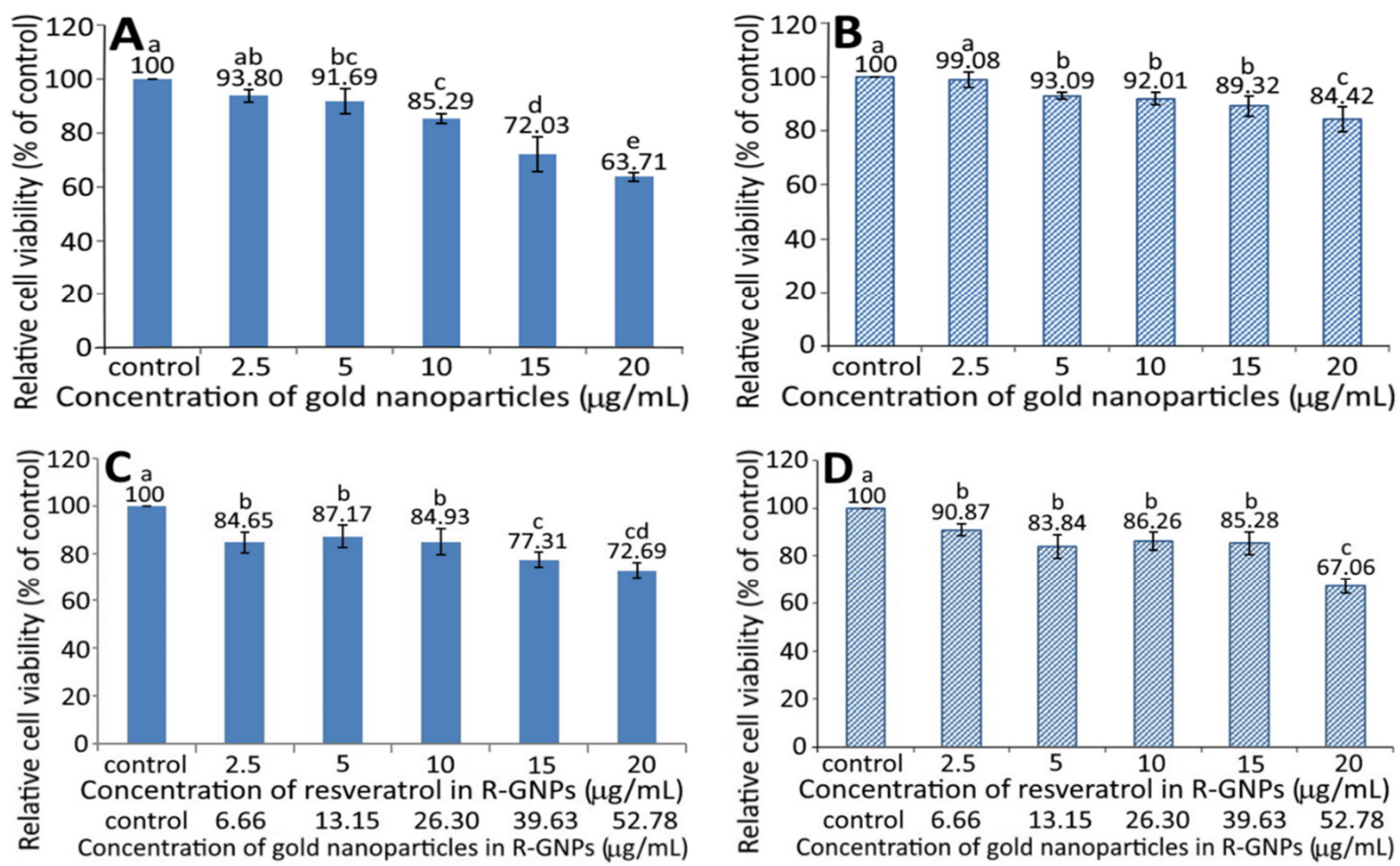

Figure 4. Effect of different concentrations of gold nanoparticles (GNPs) (A,B) and resveratrol-gold nanoparticles (R-GNPs) (C,D) on the growth of pancreatic normal cells MS1 (A,C) and pancreatic cancer cells BxPC-3 (B,D) after $48 \mathrm{~h}$ incubation as measured by MTT assay. Control represents that cells were incubated in RPMI medium only. Data are shown as mean \pm standard deviation $(n=3)$ and data with different small letters (a-e) are significantly different at $p<0.05$.

As shown above, the resveratrol and resveratrol nanoemulsion were more effective in inhibiting both pancreatic normal cells MS1 and cancer cells BxPC-3 in comparison to the GNPs and R-GNPs (Figures 4 and 5). This can be explained based on the possible activation of cell growth through localized extracellular interactions between gold nanoparticles and transmembrane signal receptors. Cancer is a complex and highly heterogeneous disease with various multidimensional factors being involved in cell growth via genomic changes. Among various factors, the dynamic interaction between cytoskeletal structures and a continuously changing extracellular matrix (ECM) plays a pivotal role in altering the genomic programming $[32,33]$. These interactions are caused by stress on integrinlike mechanosensors from multiple cellular forces and thereby activate cells' membrane focal adhesion proteins and transmembrane signal receptors [34]. Most importantly, the mechanosensors regulate cancer cell growth by triggering many phosphorylation reactions through signal transaction between a cell's extracellular active domain and intracellular F-actin filaments [35]. Consequently, it is possible that a treatment of cancer cells with nanoparticles can induce electrical polar interactions between nanoparticles in ECM and cells' mechanosensors to facilitate cancer cell growth. In a study dealing with the effect of rare-earth fluoride nanoparticles (RFNPs) on three human cancer cells (lung cancer cell A549, colon cancer cell SW837, and breast cancer cell MCF7), Semashko et al. [35] reported that unlike large RFNPs $(>20 \mathrm{~nm})$, both tiny RFNPs $(<10 \mathrm{~nm})$ and small RFNPs $(10-20 \mathrm{~nm})$ could stimulate the growth of cancer cells by electrical dipole interactions 
between RFNPs in ECM and mechanosensors. Moreover, such electrical interactions were shown to be inversely proportional to square power of RFNPs' size and depend on the electrical surface charge on both RFNPs and specific cell binding sites as well as their separating distance [35].
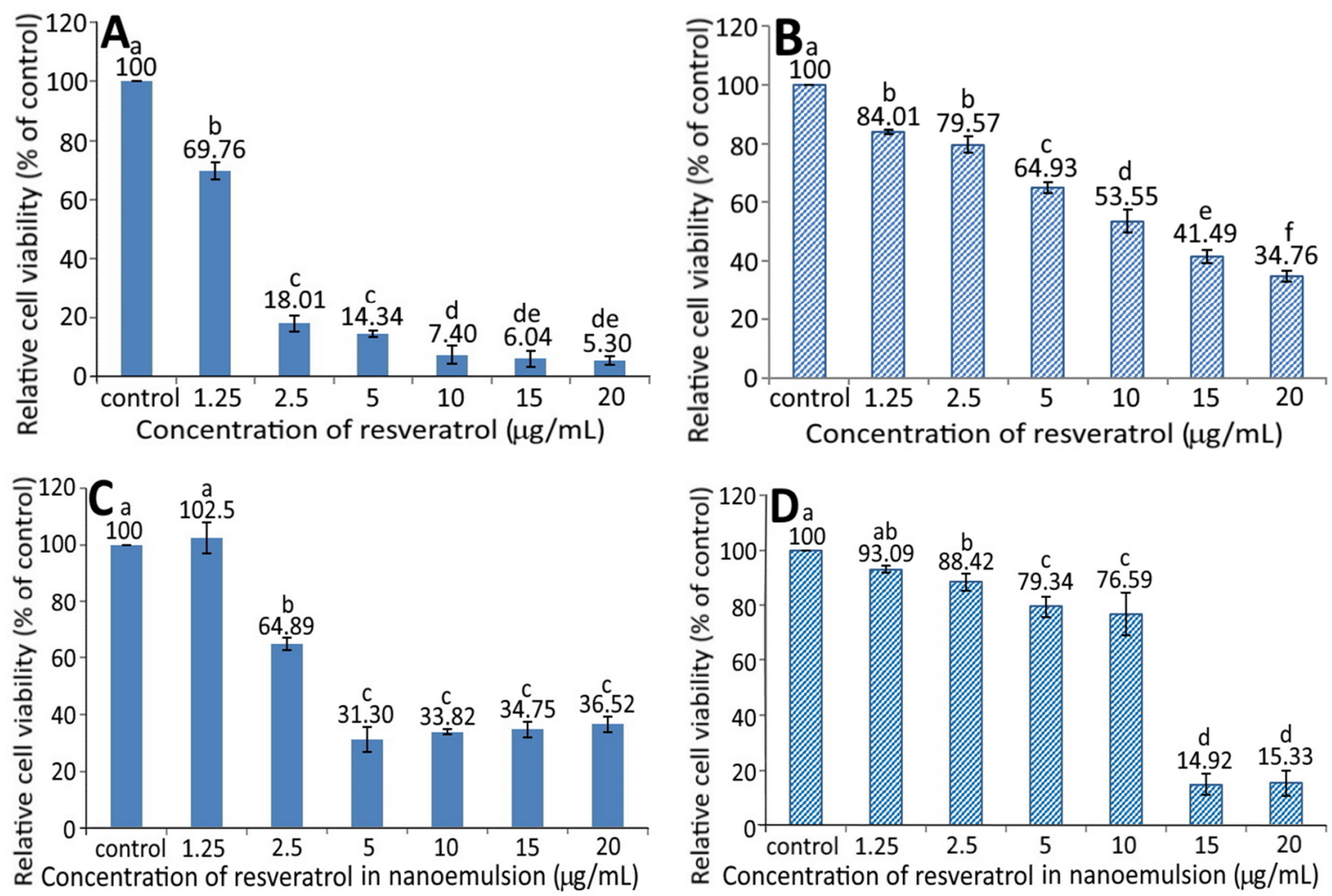

Figure 5. Effect of different concentrations of resveratrol standard $(\mathbf{A}, \mathbf{B})$ and resveratrol nanoemulsion $(\mathbf{C}, \mathbf{D})$ on the growth of pancreatic normal cells MS1 (A,C) and pancreatic cancer cells BxPC-3 (B,D) after $48 \mathrm{~h}$ incubation as measured by MTT assay. Control represents that cells were incubated in RPMI medium only. Data are shown as mean \pm standard deviation $(n=3)$ and data with different small letters $(a-f)$ are significantly different at $p<0.05$.

Thus, in our study, a higher cell viability of pancreatic cancer cells BxPC-3 for the GNPs and RGNPs compared to that for the resveratrol nanoemulsion (Figures 4 and 5) may have been caused by electrical polar interactions between the gold nanoparticles $(\leq 20 \mathrm{~nm})$ and specific cellular binding sites promoting the activation of membrane receptors and protein expression. Also, the smaller the particle size, the higher the ability to promote cell growth. However, in our study R-GNPs with particle size at $11.9 \mathrm{~nm}$ was shown to inhibit BxPC-3 cancer cell growth to a higher extent than the relatively larger-sized GNPs $(20.8 \mathrm{~nm})$. A different size effect was shown for Herceptin-coated gold nanoparticles (HGNPs) on breast cancer cells SK-BR-3, with 40 and 50 nm-sized H-GNPs showing a higher inhibition efficiency than H-GNPs at sizes $<40 \mathrm{~nm}(2,10$, and $25 \mathrm{~nm})$ [36]. Conversely, a similar trend was reported by Liu et al. [37], demonstrating that the small-sized citratecapped GNPs ( 5 and $10 \mathrm{~nm}$ ) could cause greater cytotoxicity towards lung cancer cells A549 and 95D than the large-sized ones ( 20 and $40 \mathrm{~nm}$ ), implying that both nanoparticle size and cell-type are essential determinants that can selectively affect the cell proliferation, apoptosis, cell cycle, and cell invasion. Collectively, these findings reveal that nanoparticles can actively engage in mediating molecular processes for regulating cell functions, which can be dependent upon nanoparticle size, morphology, surface charge, coating material, concentration, and composition, as well as their strength of molecular bonding with cells and cell phenotypes $[35,38,39]$. 


\subsection{Protein Expression Associated with Apoptosis}

The expression of proteins associated with the apoptosis of BxPC-3 cells, including cyclin A, cyclin B, CDK1, CDK2, Bax, BcL-2, p53, p21, and cytochrome C, is shown in Figure 6. A dose-dependent decrease in the cyclin A expression of BxPC-3 cells was shown for both the resveratrol nanoemulsion and R-GNPs treatments at a dose of 10-20 $\mu \mathrm{g} / \mathrm{mL}$ (Figure 6A). Compared to the control, the resveratrol nanoemulsion $(10 \mu \mathrm{g} / \mathrm{mL})$ increased cyclin A expression by 1.19-fold but decreased it by 0.88 - and 0.7 -fold at a dose of 15 and $20 \mu \mathrm{g} / \mathrm{mL}$, respectively, while the difference between $10 \mu \mathrm{g} / \mathrm{mL}$ and the other two doses was significantly different $(p<0.05)$. Similarly, compared to the control, the R-GNPs treatment decreased the cyclin A expression by 0.97--, 0.79-, and 0.72-fold at a dose of 10,15 , and $20 \mu \mathrm{g} / \mathrm{mL}$, respectively, while the difference between $10 \mu \mathrm{g} / \mathrm{mL}$ and the other two doses was significantly different $(p<0.05)$. Comparatively, both the resveratrol nanoemulsion and R-GNPs showed a similar inhibition effect on the cyclic A expression at the same dose. Likewise, a dose-dependent decline in the cyclin B expression was shown for both the resveratrol nanoemulsion and R-GNPs treatment at a dose from 10 to $20 \mu \mathrm{g} / \mathrm{mL}$ (Figure 6B). However, a different trend occurred for both treatments when compared at the same dose, as evident by a more pronounced inhibition effect on the cyclin $B$ expression following treatment with the resveratrol nanoemulsion. Moreover, compared to cyclin A, the resveratrol nanoemulsion showed a much higher inhibition effect on the cyclin B expression at the same dose, while the R-GNPs showed a similar inhibition effect. Accordingly, cyclin A is mainly responsible for DNA replication (S phase), while cyclin $B$ is for the preparation of materials for mitosis (G2 phase) to proceed. Thus, a dosedependent decline in the cyclin A expression may indicate that the DNA replication was gradually phased out following treatment with the resveratrol nanoemulsion. Similarly, a dose-dependent decrease in the cyclin B expression may imply that mitosis was retarded following the same treatment. In other words, pancreatic cancer cells BxPC-3 were retarded to a greater extent at $\mathrm{G} 2$ phase than at $\mathrm{S}$ phase.

Figure $6 \mathrm{C}, \mathrm{D}$ shows the CDK1 and CDK2 expressions in BxPC-3 cells as affected by both the resveratrol nanoemulsion and R-GNPs, respectively. Like cyclin A and cyclin B, a dose-dependent decrease in the CDK1 and CDK2 expressions of BxPC-3 cells was shown for both the resveratrol and R-GNPs treatments. Also, by comparison at the same dose, the resveratrol nanoemulsion showed a higher inhibition effect on the CDK1 expression than the R-GNPs. However, for the CDK2 expression, both the resveratrol nanoemulsion and R-GNPs treatments showed a similar inhibition effect as no significant difference $(p>0.05)$ was shown when compared at the same dose. Furthermore, compared to CDK2, the resveratrol nanoemulsion showed a much higher inhibition effect on the CDK1 expression at the same dose, while the R-GNPs only showed a similar inhibition effect.

For the Bax and BcL-2 expressions, a dose-dependent increase was shown for the former (Figure 6E) and a decrease for the latter (Figure 6F). By comparison, the Bax expression was raised to a much higher level for the resveratrol nanoemulsion than for the R-GNPs at the same dose, implying that the former was more efficient than the latter in elevating the Bax expression. However, a different trend was observed for the BcL-2 expression as a dose-dependent decline occurred for both the resveratrol nanoemulsion and R-GNPs treatments. Unlike the Bax expression, the resveratrol nanoemulsion showed a higher inhibition effect than the R-GNPs in inhibiting the BcL-2 expression at the same dose. This outcome clearly revealed that the resveratrol nanoemulsion was more effective than the R-GNPs in inhibiting the growth of BxPC-3 cells through the elevation of Bax expression, a pro-apoptotic protein, and the inhibition of BcL-2 expression, an anti-apoptotic protein. A similar outcome was reported by Cui, et al. [27], who studied the effect of resveratrol standard $(0-200 \mu \mathrm{M})$ on pancreatic cancer cells PAN-1, BxPC-3, and AsPC-3; a dosedependent rise in the Bax expression and decline in the BcL-2 expression were shown. 


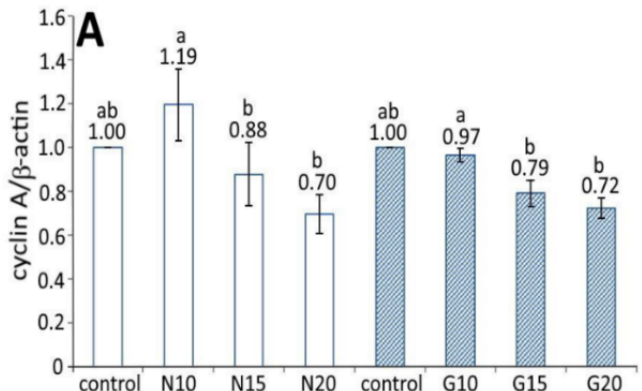

Concentration of nanoemulsion/gold nanoparticles $(\mu \mathrm{g} / \mathrm{mL})$ cyclin A -actin

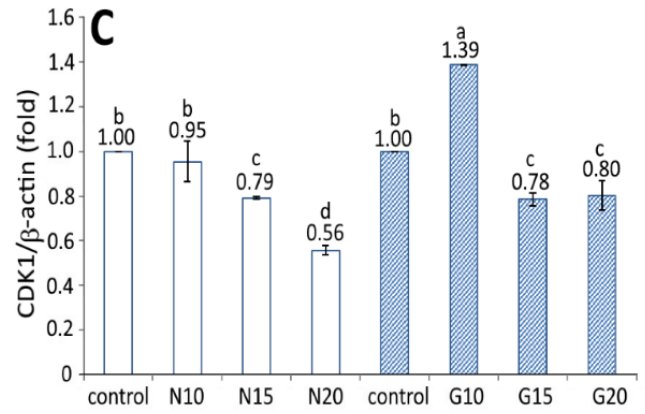

Concentration of nanoemulsion/gold nanoparticles $(\mu \mathrm{g} / \mathrm{mL})$ CDK1
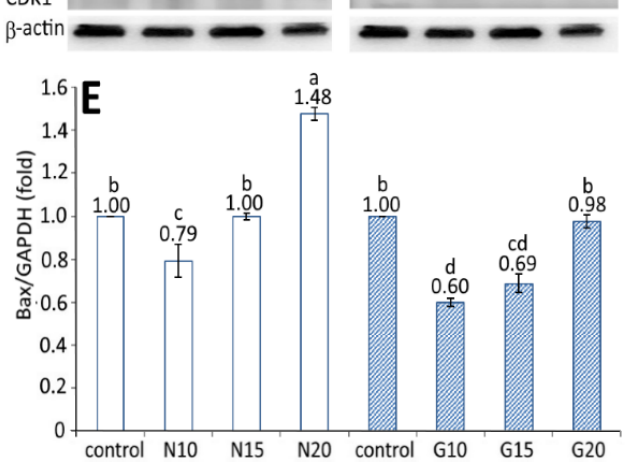

Concentration of nanoemulsion/gold nanoparticles $(\mu \mathrm{g} / \mathrm{mL})$ Bax
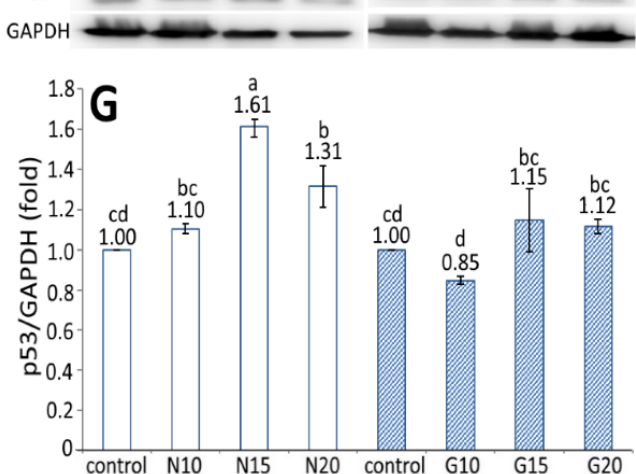

Concentration of nanoemulsion/gold nanoparticles $(\mu \mathrm{g} / \mathrm{mL})$ p53

GAPDH
${ }^{1.2} \mathbf{B}$

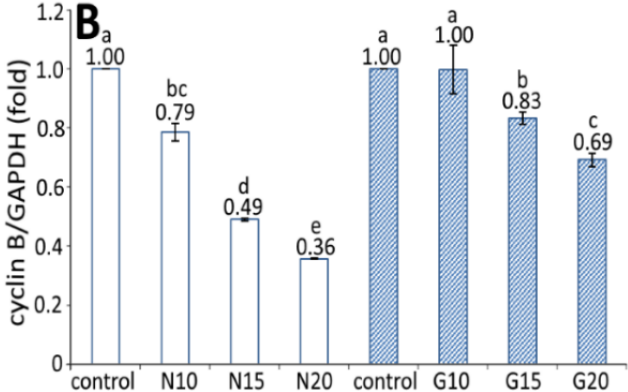

Concentration of nanoemulsion/gold nanoparticles $(\mu \mathrm{g} / \mathrm{mL}$ ) cyclin B GAPDH

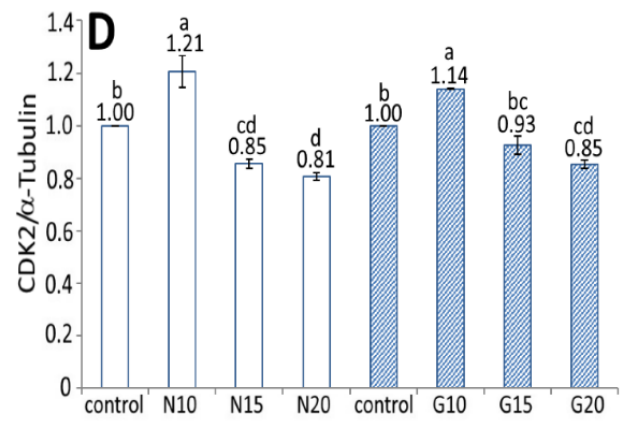

Concentration of nanoemulsion/gold nanoparticles $(\mu \mathrm{g} / \mathrm{mL}$ ) CDK2
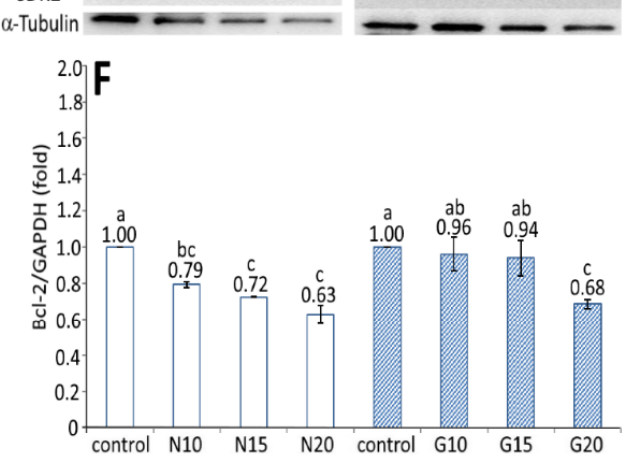

Concentration of nanoemulsion/gold nanoparticles $(\mu \mathrm{g} / \mathrm{mL})$ $\mathrm{BCl}-2$
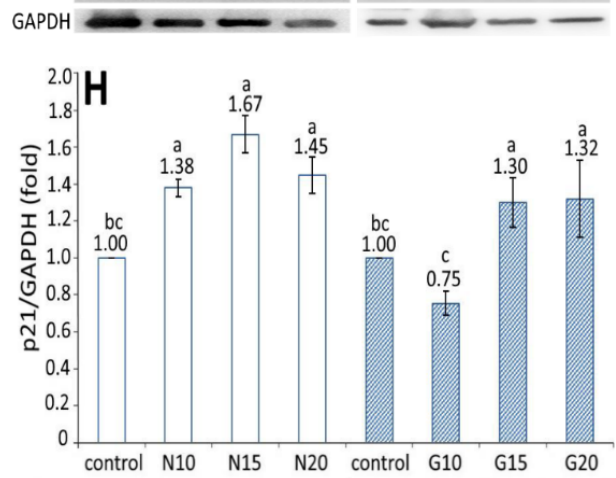

Concentration of nanoemulsion/gold nanoparticles $(\mu \mathrm{g} / \mathrm{mL})$ p21 GAPDH

Figure 6. Cont. 


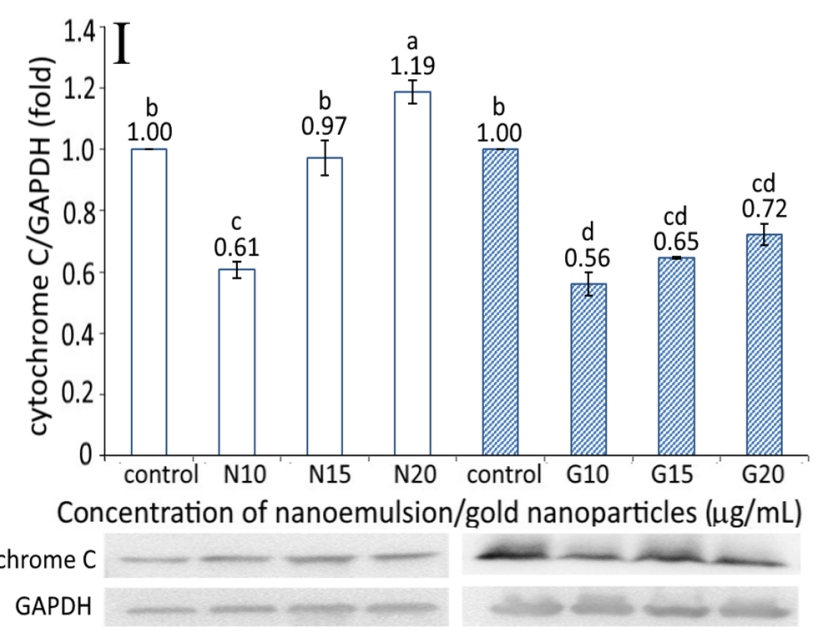

Figure 6. Effect of different concentrations (10, 15, and $20 \mu \mathrm{g} / \mathrm{mL})$ of resveratrol nanoemulsion (N) and resveratrol-gold nanoparticles (G) on cyclin A (A), cyclin B (B), CDK1 (C), CDK2 (D), Bax (E), BcL-2 (F), p53 (G), p21 (H), and cytochrome C (I) expressions in pancreatic cancer cells BxPC3. Control represents that cells were incubated in RPMI medium containing blank nanoemulsion without resveratrol $(\square)$ and gold nanoparticles without resveratrol (\$). Data are shown as mean \pm standard deviation $(n=3)$ and data with different small letters (a-e) are significantly different at $p<0.05$.

Figures $6 \mathrm{G}$ and $6 \mathrm{H}$ show the expressions of p53 and p21 in BxPC-3 cells, respectively, as affected by both the resveratrol nanoemulsion and R-GNPs. Compared to the control, only two doses of the resveratrol nanoemulsion at 15 and $20 \mu \mathrm{g} / \mathrm{mL}$ could enhance the p53 expression by 1.61- and 1.31-fold, respectively. The same trend was shown for the R-GNPs treatment at the same dose, with the p53 expression being raised by 1.15- and 1.12-fold as compared with the control. Comparatively, the resveratrol nanoemulsion could elevate the p53 expression to a higher level than the R-GNPs at the same dose. Similar findings were observed for the p21 expression, with the level being raised by 1.38-, 1.67-, and 1.45 -fold following treatment with the resveratrol nanoemulsion at 10,15 , and $20 \mu \mathrm{g} / \mathrm{mL}$, respectively, as compared to the control. For the R-GNPs treatment, the p21 expression was raised by 1.30- and 1.32-fold at a dose of 15 and $20 \mu \mathrm{g} / \mathrm{mL}$, respectively. By comparison, the resveratrol nanoemulsion could elevate both the p53 and p21 expressions to a higher level than the R-GNPs at the same dose. Furthermore, following treatment with the resveratrol nanoemulsion or R-GNPs, the p21 expression was raised to a higher level than the p53 expression at 15 and $20 \mu \mathrm{g} / \mathrm{mL}$. In several previous studies, Zhou et al. [40] studied the effect of resveratrol standard $(0-200 \mu \mathrm{M})$ on the inhibition of pancreatic cancer cells capan-2 and colo-357 and reported a rise of both the p53 and p21 expressions, accompanied by an increase of caspase- 3 activity to promote cell apoptosis.

The cytochrome $\mathrm{C}$ expression as affected by the resveratrol nanoemulsion and R-GNPs is shown in Figure 6I. A dose-dependent increase in the cytochrome C expression was shown for both the resveratrol and R-GNPs treatments. By comparison at the same dose, the resveratrol nanoemulsion was more effective in elevating the cytochrome $\mathrm{C}$ expression than the R-GNPs. This outcome also implies that resveratrol nanoemulsions could facilitate cytochrome $\mathrm{C}$ release from mitochondria to form a complex with pro-caspase- 9 for caspase9 activation to initiate cell apoptosis [14].

\subsection{Activities of Caspase-3, Caspase-8, and Caspase-9}

Figure 7 shows the effect of the resveratrol nanoemulsion and R-GNPs on activities of caspase-3, caspase-8, and caspase-9. A dose-dependent rise in activities of caspase3 , caspase-8, and caspase-9 was shown for both the resveratrol nanoemulsion and RGNPs treatments. However, by comparison at the same dose (15 and $20 \mu \mathrm{g} / \mathrm{mL})$, the resveratrol nanoemulsion showed a significantly higher $(p<0.05)$ caspase- 9 activity than 
the R-GNPs, but no significant difference $(p>0.05)$ was observed for either the caspase-3 or caspase-8 activities. Accordingly, cell apoptosis can be regulated through death receptor, mitochondria, or endoplasmic reticulum pathways, in which the caspase protein plays a vital role in cell apoptosis. More specifically, following a decrease in BcL-2 expression, cytochrome $C$ can be released from mitochondria to form a complex with pro-caspase- 9 for caspase-9 activation for apoptosis initiation through the mitochondria pathway. In addition, caspase- 8 can be activated through the death receptor pathway for the initiation of apoptosis, while caspase 3 can be activated through both mitochondria and death receptor pathways for the execution of apoptosis. As a high dose $(20 \mu \mathrm{g} / \mathrm{mL})$ of both the resveratrol nanoemulsion and R-GNPs showed a significantly higher $(p<0.05)$ caspase-3 activity than that of the control, this finding suggests that both death receptor and mitochondria pathways may be responsible for the apoptosis of BxPC-3 cells. In several similar studies, Mouria et al. [41] also reported that both cytochrome $C$ and caspase-3 activities were elevated following the treatment of pancreatic cancer cells Mia-PACA-2 with resveratrol standard $(25 \mu \mathrm{M})$. Similarly, the caspase-3 and PARP activities were raised following the treatment of pancreatic cancer cells PANC- 1 and BxPC-3 with resveratrol standard $(50 \mu \mathrm{M})$ [42]. A dose of resveratrol standard $(50 \mu \mathrm{M})$ could raise activities of caspase-3, caspase-8, and caspase- 9 in both pancreatic cancer cells PANC-1 and BxPC-3, while a dose of $100 \mu \mathrm{M}$ could also raise all the caspase activities in pancreatic cancer cells AsPC-3 [27]. Additionally, both Bax and caspase-3 expressions were enhanced while BcL-2 expression decreased following the treatment of pancreatic cancer cells MiaPaCa-2 with resveratrol standard at $100 \mu \mathrm{M}[43]$.
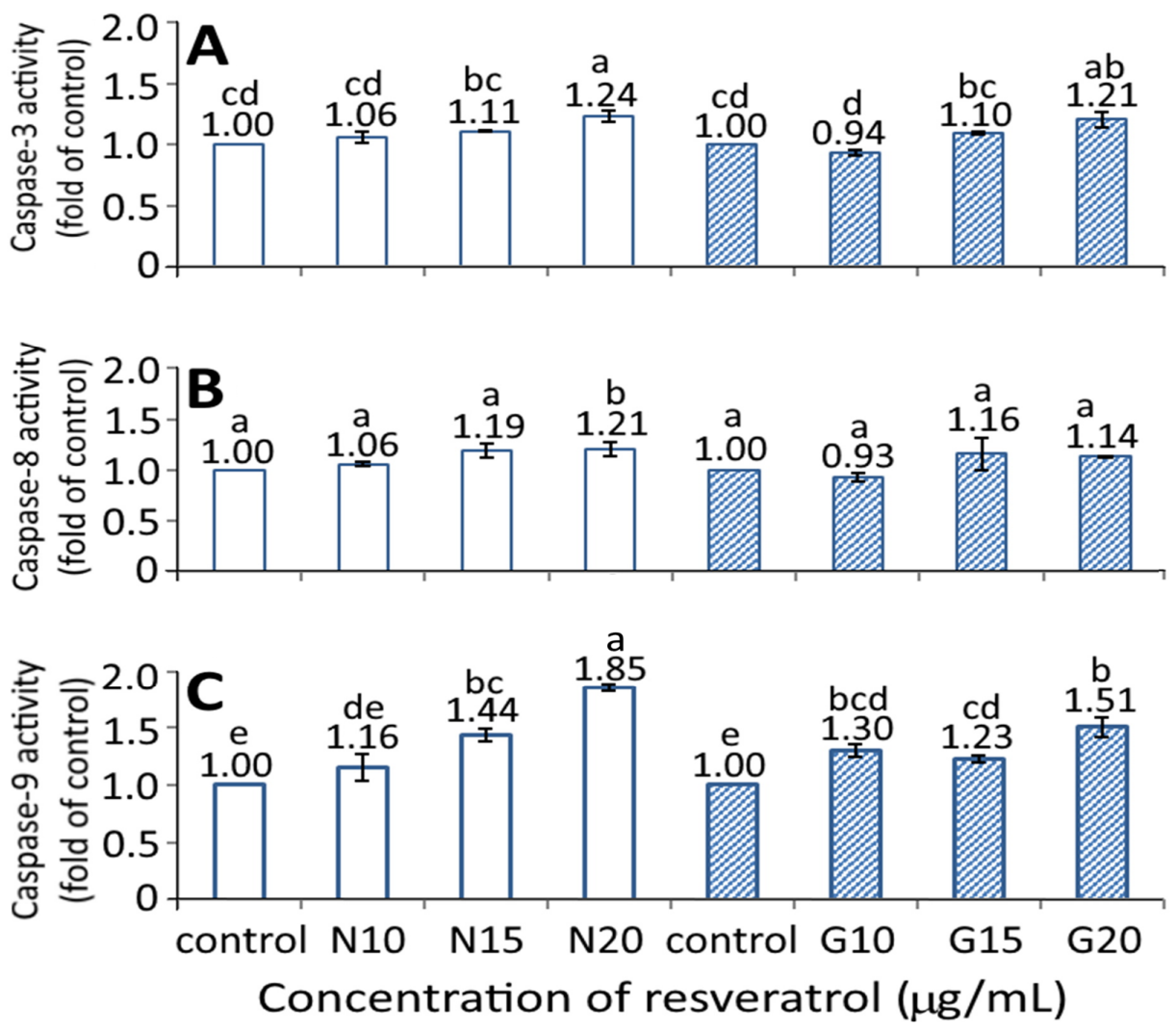

Figure 7. Effect of different concentrations (10, 15, and $20 \mu \mathrm{g} / \mathrm{mL})$ of resveratrol nanoemulsion and resveratrol-gold nanoparticles on caspase-3 (A), caspase-8 (B), and caspase-9 (C) activities of pancreatic cancer cells BxPC-3. Control represents that cells were incubated in RPMI medium containing blank nanoemulsion without resveratrol $(\square)$ and gold nanoparticles without resveratrol (迤). N and G represent resveratrol nanoemulsion and resveratrol-gold nanoparticles, respectively. Data are shown as mean \pm standard deviation $(n=3)$ and data with different small letters (a-e) are significantly different at $p<0.05$. 


\section{Conclusions}

Collectively, in our study both the resveratrol nanoemulsion prepared from grape skin and the R-GNPs from gold and resveratrol standard could inhibit the growth of pancreatic cancer cells BxPC-3 through the inhibition of cyclin A, cyclin B, CDK1, and CDK2 expressions and the elevation of both p53 and p21 expressions. Meanwhile, the Bax expression was enhanced and BcL-2 expression inhibited to reduce mitochondria membrane potential for cytochrome $\mathrm{C}$ release from mitochondria for the activation of both caspase- 8 and caspase- 9 for initiation of the apoptosis, followed by the activation of caspase3 for the execution of apoptosis of BxPC-3 cells. Further research is necessary to study the inhibition of pancreatic tumors in vivo by resveratrol nanoemulsions and R-GNPs.

Supplementary Materials: The following are available online at https:/ / www.mdpi.com/article/10 .3390 / pharmaceutics13111871/s1, Table S1: Changes in particle size and zeta potential of resveratrol nanoemulsion during heating at $40-100{ }^{\circ} \mathrm{C}$ for varied time length.

Author Contributions: Conceptualization, B.-H.C.; data curation, B.S.I. and L.-H.H.; formal analysis, B.S.I. and L.-H.H.; funding acquisition, B.-H.C.; investigation, B.S.I. and L.-H.H.; methodology, B.S.I. and L.-H.H.; project administration, B.-H.C.; resources, B.-H.C.; software, B.S.I. and L.-H.H.; validation, B.S.I. and L.-H.H.; writing—original draft preparation, B.-H.C., B.S.I. and L.-H.H.; writingreview and editing, B.-H.C. and B.S.I.; visualization, B.S.I. and L.-H.H.; supervision, B.-H.C. All authors have read and agreed to the published version of the manuscript.

Funding: This research was funded by the Ministry of Science and Technology Taiwan (grant number 106-2320-B-030-007-MY2).

Institutional Review Board Statement: This article does not contain any studies with human or animal subjects performed by any of the authors.

Informed Consent Statement: Not applicable.

Data Availability Statement: Not applicable.

Acknowledgments: The authors wish to thank Yen-Sheng Wu from Tzong Jao Hang's Electron Microscope Laboratory, School of Medicine, Fu Jen Catholic University, New Taipei City, Taiwan for technical assistance in recording TEM images.

Conflicts of Interest: The authors declare no conflict of interest.

\section{References}

1. Perestrelo, R.; Silva, C.; Pereira, J.; Câmara, J.S. Healthy effects of bioactive metabolites from Vitis vinifera L. grapes: A review. In Grapes: Production, Phenolic Composition and Potential Biomedical Effects; Camara, J.S., Ed.; Nova Science Publishers: Hauppauge, NY, USA, 2014; Chapter 12; pp. 305-338.

2. Ko, J.-H.; Sethi, G.; Um, J.-Y.; Shanmugam, M.K.; Arfuso, F.; Kumar, A.P.; Bishayee, A.; Ahn, K.S. The role of resveratrol in cancer therapy. Int. J. Mol. Sci. 2017, 18, 2589. [CrossRef]

3. Wahab, A.; Gao, K.; Jia, C.; Zhang, F.; Tian, G.; Murtaza, G.; Chen, J. Significance of resveratrol in clinical management of chronic diseases. Molecules 2017, 22, 1329. [CrossRef]

4. Shrikanta, A.; Kumar, A.; Govindaswamy, V. Resveratrol content and antioxidant properties of underutilized fruits. J. Food Sci. Technol. 2013, 52, 383-390. [CrossRef]

5. Kuršvietienè, L.; Stanevičienè, I.; Mongirdienè, A.; Bernatonienè, J. Multiplicity of effects and health benefits of resveratrol. Medicina 2016, 52, 148-155. [CrossRef]

6. Marier, J.F.; Vachon, P.; Gritsas, A.; Zhang, J.; Moreau, J.-P.; Ducharme, M.P. Metabolism and disposition of resveratrol in rats: Extent of absorption, glucuronidation, and enterohepatic recirculation evidenced by a linked-rat model. J. Pharmacol. Exp. Ther. 2002, 302, 369-373. [CrossRef] [PubMed]

7. Acosta, E. Bioavailability of nanoparticles in nutrient and nutraceutical delivery. Curr. Opin. Colloid Interface Sci. 2009, 14, 3-15. [CrossRef]

8. McClements, D.J. Nanoemulsions versus microemulsions: Terminology, differences, and similarities. Soft Matter 2011, 8, 1719-1729. [CrossRef]

9. Huang, R.-F.S.; Wei, Y.-J.; Inbaraj, B.S.; Chen, B.H. Inhibition of colon cancer cell growth by nanoemulsion carrying gold nanoparticles and lycopene. Int. J. Nanomed. 2015, 10, 2823-2846. [CrossRef]

10. Coulter, J.A.; Jain, S.; Butterworth, K.T.; Taggart, L.; Dickson, G.; McMahon, S.J.; Hyland, W.B.; Muir, M.F.; Trainor, C.; Hounsell, A.; et al. Cell type-dependent uptake, localization, and cytotoxicity of $1.9 \mathrm{~nm}$ gold nanoparticles. Int. J. Nanomed. 2012, 7, 2673-2685. [CrossRef] 
11. Lu, W.; Zhang, G.; Zhang, R.; Flores, L.G.; Huang, Q.; Gelovani, J.G.; Li, C. Tumor site-specific silencing of NF-kB p65by Targeted Hollow Gold Nanosphere-Mediated Photothermal Transfection. Cancer Res. 2010, 70, 3177-3188. [CrossRef] [PubMed]

12. Wang, D.-G.; Liu, W.-Y.; Chen, G.-T. A simple method for the isolation and purification of resveratrol from Polygonum cuspidatum. J. Pharm. Anal. 2012, 3, 241-247. [CrossRef]

13. Hua, L.; Inbaraj, B.S.; Chen, B. An improved analytical method for determination of trans-resveratrol and related stilbenes in grape skin by QuEChERS coupled with HPLC-PDA-MS. Int. J. Food Sci. Technol. 2021, in press. [CrossRef]

14. Yang, C.-C.; Hung, C.-F.; Chen, B.-H. Preparation of coffee oil-algae oil-based nanoemulsions and the study of their inhibition effect on UVA-induced skin damage in mice and melanoma cell growth. Int. J. Nanomed. 2017, 12, 6559-6580. [CrossRef] [PubMed]

15. Kimling, J.; Maier, M.; Okenve, B.; Kotaidis, V.; Ballot, H.; Plech, A. Turkevich method for gold nanoparticle synthesis revisited. J. Phys. Chem. B 2006, 110, 15700-15707. [CrossRef]

16. Inbaraj, B.S.; Chen, B.-Y.; Liao, C.-W.; Chen, B.-H. Green synthesis, characterization and evaluation of catalytic and antibacterial activities of chitosan, glycol chitosan and $\operatorname{poly}(\gamma$-glutamic acid) capped gold nanoparticles. Int. J. Biol. Macromol. 2020, 161, 1484-1495. [CrossRef]

17. Thipe, V.C.; Amiri, K.P.; Bloebaum, P.; Raphael, A.K.; Khoobchandani, M.; Katti, K.K.; Jurisson, S.S.; Katti, K.V. Development of resveratrol-conjugated gold nanoparticles: Interrelationship of increased resveratrol corona on anti-tumor efficacy against breast, pancreatic and prostate cancers. Int. J. Nanomed. 2019, 14, 4413-4428. [CrossRef] [PubMed]

18. SAS. SAS Procedures and SAS/Graph User's Guide; Version 6; SAS: Cary, NC, USA, 2014.

19. Sessa, M.; Tsao, R.; Liu, R.; Ferrari, G.; Donsì, F. Evaluation of the stability and antioxidant activity of nanoencapsulated resveratrol during in vitro digestion. J. Agric. Food Chem. 2011, 59, 12352-12360. [CrossRef] [PubMed]

20. Kumar, R.; Kaur, K.; Uppal, S.; Mehta, S. Ultrasound processed nanoemulsion: A comparative approach between resveratrol and resveratrol cyclodextrin inclusion complex to study its binding interactions, antioxidant activity and UV light stability. Ultrason. Sonochem. 2017, 37, 478-489. [CrossRef]

21. Xiong, Y.; Li, S.; Warner, R.D.; Fang, Z. Effect of oregano essential oil and resveratrol nanoemulsion loaded pectin edible coating on the preservation of pork loin in modified atmosphere packaging. Food Control 2020, 114, 107226. [CrossRef]

22. Shnoudeh, A.J.; Hamad, I.; Abdo, R.W.; Qadumii, L.; Jaber, A.Y.; Surchi, H.S.; Alkelany, S.Z. Synthesis, characterization, and applications of metal nanoparticles. In Biomaterials and Bionanotechnology; Chapter 15; Tekade, R.K., Ed.; Academic Press: Cambridge, MA, USA, 2019; pp. 527-612.

23. Zhou, J.; Zhou, M.; Yang, F.-F.; Liu, C.-Y.; Pan, R.-L.; Chang, Q.; Liu, X.-M.; Liao, Y.-H. Involvement of the inhibition of intestinal glucuronidation in enhancing the oral bioavailability of resveratrol by labrasol containing nanoemulsions. Mol. Pharm. 2015, 12, 1084-1095. [CrossRef]

24. Tomoaia, G.; Horovitz, O.; Mocanu, A.; Nita, A.; Avram, A.; Racz, C.P.; Soritau, O.; Cenariu, M.; Tomoaia-Cotisel, M. Effects of doxorubicin mediated by gold nanoparticles and resveratrol in two human cervical tumor cell lines. Colloids Surf. B Biointerfaces 2015, 135, 726-734. [CrossRef] [PubMed]

25. Park, S.; Cha, S.-H.; Cho, I.; Park, S.; Park, Y.; Cho, S.; Park, Y. Antibacterial nanocarriers of resveratrol with gold and silver nanoparticles. Mater. Sci. Eng. C 2016, 58, 1160-1169. [CrossRef] [PubMed]

26. Zhang, D.; Zhang, J.; Zeng, J.; Li, Z.; Zuo, H.; Huang, C.; Zhao, X. Nano-gold loaded with resveratrol enhance the anti-hepatoma effect of resveratrol in vitro and in vivo. J. Biomed. Nanotechnol. 2019, 15, 288-300. [CrossRef] [PubMed]

27. Cui, J.; Sun, R.; Yu, Y.; Gou, S.; Zhao, G.; Wang, C. Antiproliferative effect of resveratrol in pancreatic cancer cells. Phytother. Res. 2010, 24, 1637-1644. [CrossRef] [PubMed]

28. Kim, T.H.; Shin, Y.J.; Won, A.J.; Lee, B.M.; Choi, W.S.; Jung, J.H.; Chung, H.Y.; Kim, H.S. Resveratrol enhances chemosensitivity of doxorubicin in multidrug-resistant human breast cancer cells via increased cellular influx of doxorubicin. Biochim. Biophys. Acta (BBA)-Gen. Subj. 2013, 1840, 615-625. [CrossRef]

29. Holian, O.; Walter, R.J. Resveratrol inhibits the proliferation of normal human keratinocytes in vitro. J. Cell. Biochem. Suppl. 2001, 81, 55-62. [CrossRef]

30. Haider, U.G.B.; Sorescu, D.; Griendling, K.; Vollmar, A.M.; Dirsch, V. Resveratrol increases serine15-phosphorylated but transcriptionally impaired p53 and induces a reversible DNA replication block in serum-activated vascular smooth muscle cells. Mol. Pharmacol. 2003, 63, 925-932. [CrossRef]

31. Igura, K.; Ohta, T.; Kuroda, Y.; Kaji, K. Resveratrol and quercetin inhibit angiogenesis in vitro. Cancer Lett. 2001, 171, 11-16. [CrossRef]

32. Butcher, D.T.; Alliston, T.; Weaver, V.M. A tense situation: Forcing tumour progression. Nat. Rev. Cancer 2009, 9, 108-122. [CrossRef]

33. Tracqui, P. Biophysical models of tumour growth. Rep. Prog. Phys. 2009, 72, 056701. [CrossRef]

34. Khalili, A.A.; Ahmad, M.R. A review of cell adhesion studies for biomedical and biological applications. Int. J. Mol. Sci. 2015, 16, 18149-18184. [CrossRef] [PubMed]

35. Semashko, V.V.; Pudovkin, M.S.; Cefalas, A.-C.; Zelenikhin, P.V.; Gavriil, V.E.; Nizamutdinov, A.S.; Kollia, Z.; Ferraro, A.; Sarantopoulou, E. Tiny rare-earth fluoride nanoparticles activate tumour cell growth via electrical polar interactions. Nanoscale Res. Lett. 2018, 13, 370. [CrossRef] [PubMed]

36. Jiang, W.; Kim, B.Y.; Rutka, J.T.; Chan, W.C.W. Nanoparticle-mediated cellular response is size-dependent. Nat. Nanotechnol. 2008, 3, 145-150. [CrossRef]

37. Liu, Z.; Wu, Y.; Guo, Z.; Liu, Y.; Shen, Y.; Zhou, P.; Lu, X. Effects of internalized gold nanoparticles with respect to cytotoxicity and invasion activity in lung cancer cells. PLoS ONE 2014, 9, e99175. [CrossRef] [PubMed] 
38. Jiang, Y.; Huo, S.; Mizuhara, T.; Das, R.; Lee, Y.-W.; Hou, S.; Moyano, D.F.; Duncan, B.; Liang, X.-J.; Rotello, V.M. The interplay of size and surface functionality on the cellular uptake of sub-10 nm gold nanoparticles. ACS Nano 2015, 9, 9986-9993. [CrossRef]

39. Rauch, J.; Kolch, W.; Laurent, S.; Mahmoudi, M. Big signals from small particles: Regulation of cell signaling pathways by nanoparticles. Chem. Rev. 2013, 113, 3391-3406. [CrossRef]

40. Zhou, J.-H.; Cheng, H.-Y.; Yu, Z.-Q.; He, D.-W.; Pan, Z.; Yang, D.-T. Resveratrol induces apoptosis in pancreatic cancer cells. Chin. Med. J. 2011, 124, 1695-1699. [CrossRef]

41. Mouria, M.; Gukovskaya, A.S.; Jung, Y.; Buechler, P.; Hines, O.J.; Reber, H.A.; Pandol, S.J. Food-derived polyphenols inhibit pancreatic cancer growth through mitochondrial cytochrome $C$ release and apoptosis. Int. J. Cancer 2002, 98, 761-769. [CrossRef]

42. Duan, J.; Yue, W.; JianYu, E.; Malhotra, J.; Lu, S.-E.; Gu, J.; Xu, F.; Tan, X.-L. In vitro comparative studies of resveratrol and triacetylresveratrol on cell proliferation, apoptosis, and STAT3 and NFkB signaling in pancreatic cancer cells. Sci. Rep. 2016, 6, 31672. [CrossRef]

43. Zhu, M.; Zhang, Q.; Wang, X.; Kang, L.; Yang, Y.; Liu, Y.; Yang, L.; Li, J.; Yang, L.; Liu, J.; et al. Metformin potentiates anti-tumor effect of resveratrol on pancreatic cancer by down-regulation of VEGF-B signaling pathway. Oncotarget 2016, 7, 84190-84200. [CrossRef] 